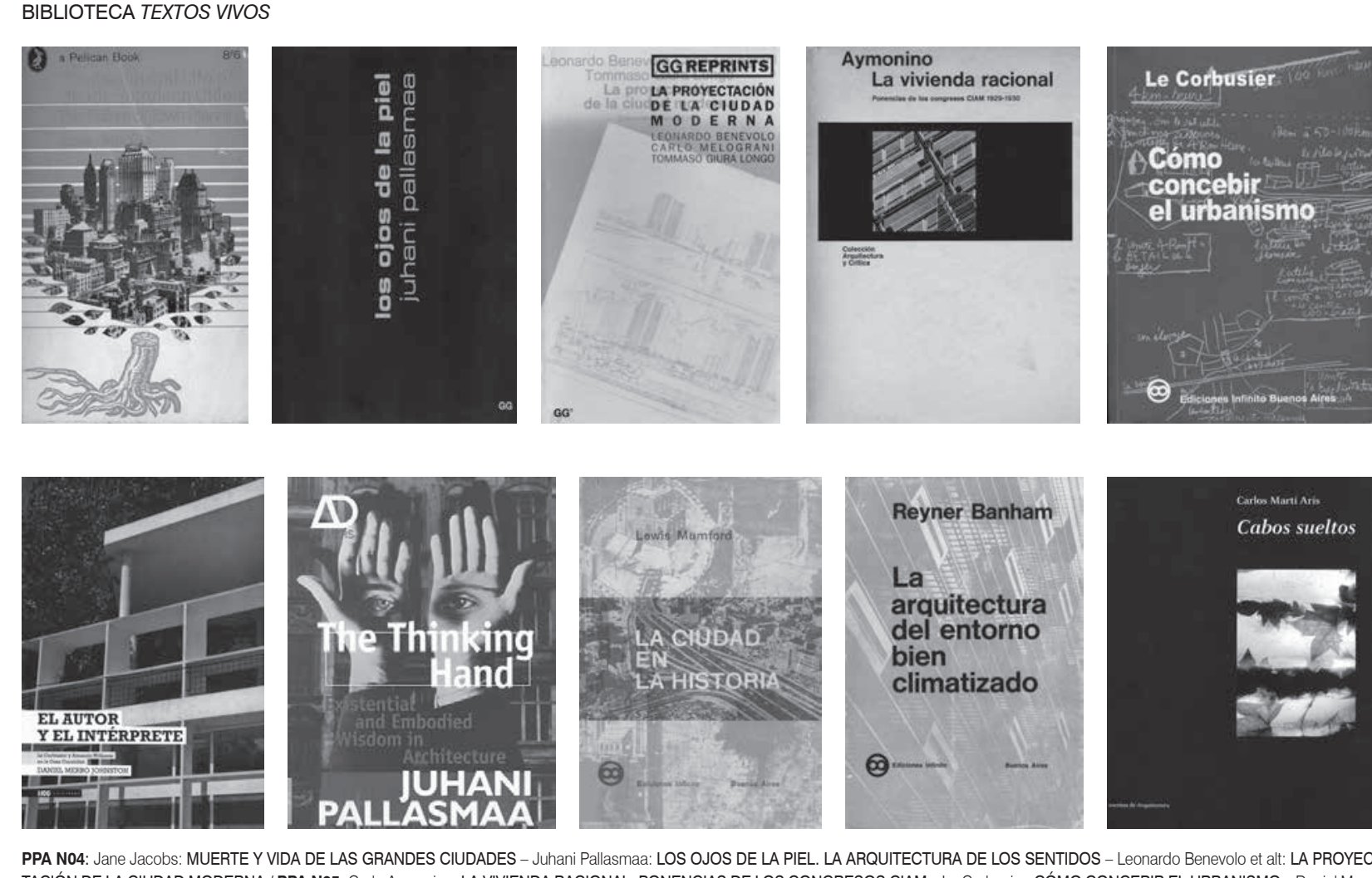

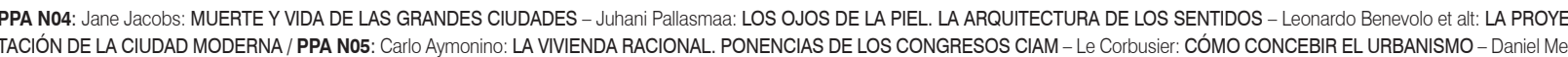

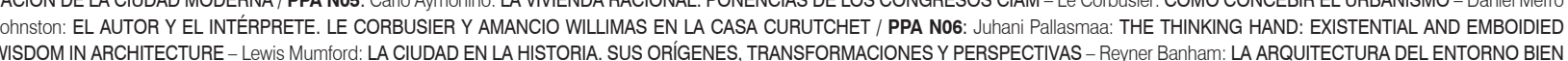
CLMMATZADO/ / PPA NOT: Carlos Martíi Aris: AABOS SUELTOS

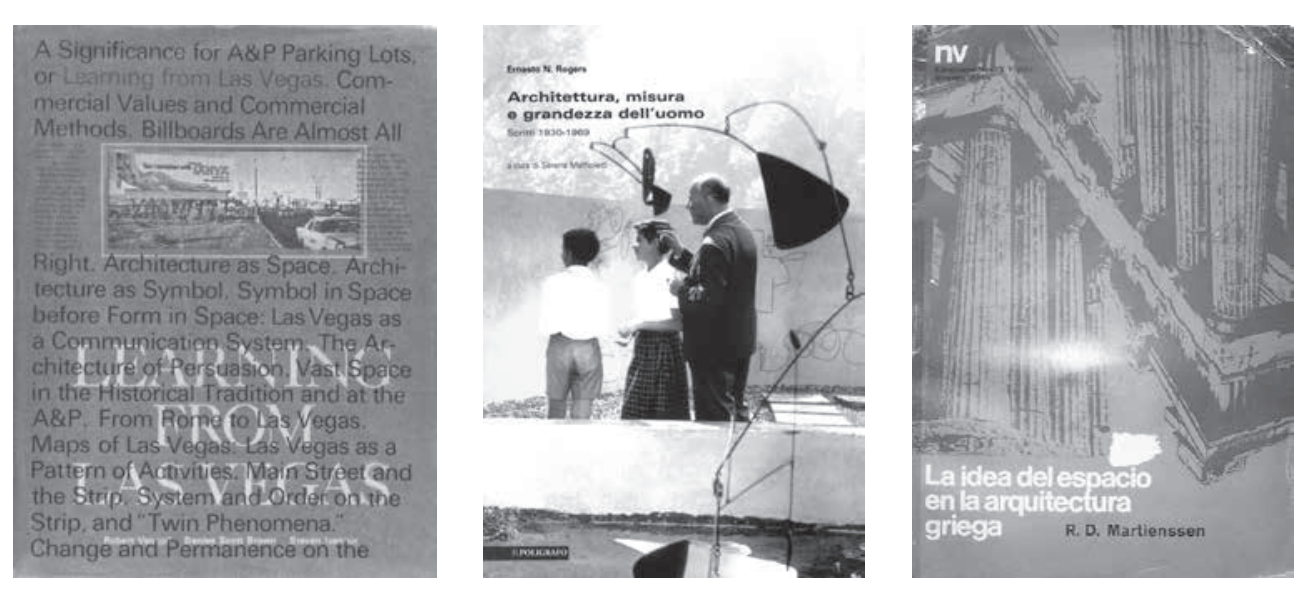

PPA No8

Robert Venturi, Denise Scotit Brown y Steven
DEZA DELL'UOMO. SCRIITT $1930-1969$

PPA No9

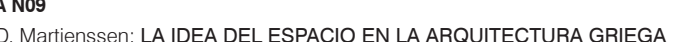

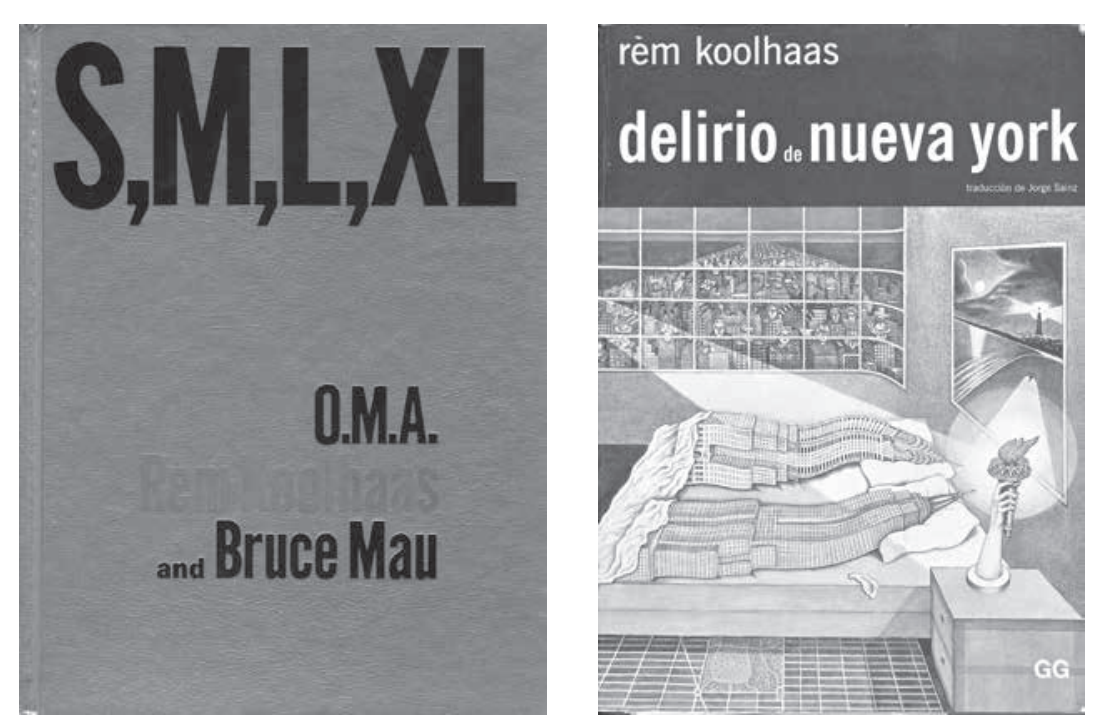

reseña bibliográfica TEXTOS VIVOS

Nuestra época está sometida a transformaciones hasta ahora insospechadas a cuya aparición no somos ajenos y que afectan a la forma de entender y practicar la arquitectura. El entendimiento y la acción en la nueva arquitectura no deben abordarse solo desde la cultura y de nuestra participación en ella a lo largo del tiempo y en la evorín de nuestra

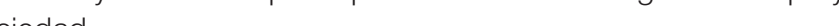

Cada tiempo, y el nuestro también, decide qué arquitectos y cuáles textos y obras han de ser rescatados y recalificados como clásicos.

Mediante el diálogo con ellos, los arquitectos actuales nos alinearemos en la tradición

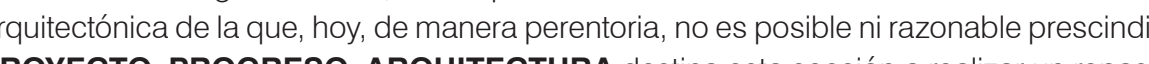

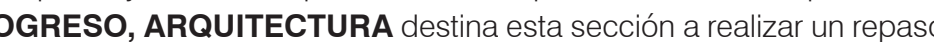
propositivo y abierto a esos textos. 


\section{REM KOOLHAAS: SMALL, MEDIUM, LARGE, EXTRA-LARGE}

Editado por Jennifer Sigler. Rotterdam: 010, 1995

Alfonso del Pozo y Barajas,

Dr. Arquitecto. Profesor Titular de Universidad. Departamento de Proyectos Arquitectónicos. Escuela Técnica Superior de Arquitectura. Un

Persona de contacto: adel|@@arrakis.es

E n 1995 Rem Koolhaas publica este libro singular. Su mayor parte está dedicada a exponer los - proyectos y obras de OMA desde sus orígenes hasta 1993. Citare aqui cuatro de ellos, que nos permitirán paladear la arquitectura de este controvertido arquitecto. Nuestro hilo conductor será mismo que el utilizó: las escalas, que ciertamente definen el carácter de sus edificios más allá de cualquier otra consideración.

S VILLA DALL'AVA, PARíS, 1985-1991. Es la más temprana de las obras y, también, la más pequeña. Una vivienda unifamiliar que esconde un proyecto de largo aliento. Koolhaas dedica a su exposición nada menos que 63 páginas, volcadas en una minuciosa y reiterada recreación, mayoritariamente grá́ica.

El autor abordó el proyecto mediante una estrategia que luego ha utilizado otras veces, a distintas escalas: En primer lugar establece una división en tres franjas de distinto carácter, orientadas en el sentido do la profundidad de la parcela, para interponer luego varias bandas transversales, también desiguales. De la

teracción de ambas familias geometricas surgirán los contenidos más jugosos del proyecto.

M PALACIO DE CONGRESOS, AGADIR, 1990. Como hiciera Le Corbusier, o Speer, Rem Koolhaas no ha tenido reparos en obviar la catadura moral de sus patronos, viéndolos sólo como los agentes necesarios para hacer su arquitectura. Aqui tenemos un ejemplo, en la entrada de este concurso para crear un enclave de la jet en la costa marroquil. Vedado a la inmensa mayoría de los habitantes de este pais tercermundista, su programa lo dice todo: se trataba de erigir un centro de convenciones, que sirviera de seria y elegante excusa a un hotel, un casino, un night club y una tastuosa cámara real para Hassan II.

Dicho esto, les introduciré a esta obra de arte. Nada, salvo las dunas, el mar, el cielo y la vía de acceso condiciona el proyecto. Como hace a menudo en estos casos, Koolhaas impone, como primera medida de control, la construcción de un perímetro basado en el angulo recto. Tenemos asíya, por mera extrusión de la planta, un blanco prisma de base cuadrangular. Hasta aquí, las semejanzas con el origen de tantos proyectos de, porejemplo, unCampo Baeza. Incapazde proseguirporlasendade los apolíneos, el dionisíaco Remrompe horizontal y brutalmente la caja en dos mitades. Cada trozo adquiere cualidades distintivas: así, la parte baja convierte su cara superior en un molde insólito de las dunas cuyo sitio viene a ocupar, en tanto que la alta también adopta una topografia, mas libre, en su cara inferior. Entre ambas partes demediadas se abre una griet que adopta múltiples conformaciones espaciales, cambiantes desde la escala de la fisura a la de la gruta L ESTACIÖN MARITIMAA, ZEEBRUGGE, 1989. La inminente terminación del túnel del Canal de la Mancha se convirtió en una amenaza para las navieras que cubrían el tráfico de ferries. Una de ellas convocó un concurso para implementar su sede. No solicitaba sölo una mejora funcional: buscaba una imagen que edujera al público y le hiciera acudir a disfrutarla, antes o despues de tomar el feriy

Koolhaas respondio diseñando una Babel eficiente, capaz de manejar el vasto programa de flujos de un intercambiador, sin perder de vista la satisfacción de las demandas icónicas. El resultado fue un objeto arom formado por un ironco de cono coronado por de somiestera, que asume y redistribuye el tráfico $\mathrm{de}$ A partir de ań A partir de ahi la secclion cambia drásticamente, para asumir sendos desarrollos en vertical que sajan la

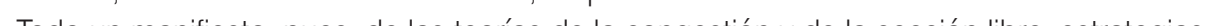

Todo un manifiesto, pues, de las teorlas de la congestión y de la sección libre, estrateglas revolucionarias de proyeclación que el arquilecto habla descubletto años atrás en Manhatan, y que consignó en Delf-

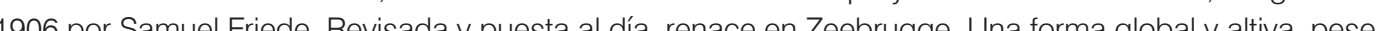

XLCIUDAD AEROPUERTODESEULL, 1995. EnlosnoventaKoolhaascomienzaaprestaratenciónalosfenómenosdecrecimientoaceleradoqueseestándandoenAsia. Noeselunicoarquitectooccidentalenhacerlo, pero

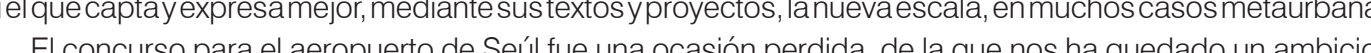
El concurso para el aeropuerto de Seúl fue una ocasión perdida, de la que nos ha quedado un ambicioso proyecto urbano. No aparece en el libro -son coetáneos-, aunque si encontramos en el un antecedente directo: el utópico traslado del aeropuerto de Schipol al Canal de la Mancha. Seul es una ciudad costera, compleja y abigarrada. En frente de su bahia hay un archipielago paradisiaco. Como en Agadir, el arquitecto reacciona ante este paisaje desbordante con una primera operación, de imposición de un orden geométrico. Asi, sitúa el aeropuerto en el mar, junto a un islote, y crea una una nueva isla entre este y Seúl, puerto que talla en medio de resonancias manhattanianas, $q$

TEXTOS Koolhaas salpica el volumen con una veintena. Entre los mejores distinguire un primer grupo: de los relacionados con su trayectia intelua recientes, desarrollan algunos aspectos relacionados con la misma. De ell y muy lejanos en el tiempo, por lo que debemos considerar su inclusión aqui como un autohomenaje. Me refiero al Summer Surdy (1970) y al proyeclo Fin de Carrera (1972), a los que se une el no tan interesante Apéndice de Delirious New York. A ellos debemos unir "Bigness, or the problem of Large" (1994), tercer desarrollo del concepto de lo "enorme"; y, finalmente, "Last Apples" (1993), uno de los pocos en que ahonda en temas estructurales.

El segundo grupo marca un punto de inflexión, al abrir un campo de investigación volcado al conocimiento de los nuevos procesos urbanos. En "Atlanta" (1987/1994) describe el presente de esa ciudad desprovista de centro y, por ello, potencialmente policéntrica, utilizando claves de interpretación alejadas tanto de las del urbanismo convencional como de las que él mismo había desentrañado en Manhattan. es que aquella urbe fascinante en la que un joven Rem halló el paradigma de la modernidad no es, y así lo reconoce, un referente válido para nuestro tiempo. "What ever happened to Urbanism?" (1994) es un colofón de "Atlanta", transcrito en tono apocalíptico: apoyado en los inauditos crecimientos de algunas urbes del subdesarrollo, Koolhaas decreta la muerte del urbanismo, incapaz de prever y gestionar los vertiginosos cambios de lo urbano. Luego comienza a pergeñar una idea alternativa de esta ciencia, aún no bien madurada, cuya premisa ha de ser la de aceptar lo que existe. En consecuencia, el arquitecto describe en Singapore Songlines" (1995) los procesos operados en una metápolis emergente, que han cambiado su taz en tan sólo treinta años. Ésta es la investigación de más calado que encierra el libro. Un trabajo analitico coronado solo a medias por el exito: la realidad ultima de esta megalopolis se nos escurre entre los dedos. Finalmente, el mayor esfuerzo de sintesis se da en "The Generic City" (1994). En el no se examinan casos de ciudades, sino que se plantea una primera teorización de la ciudad contemporánea. No obstante, su brevedad le piva de alcanzar rosulados concluyentes. es más un indice que un tralado sobre lo urbano.

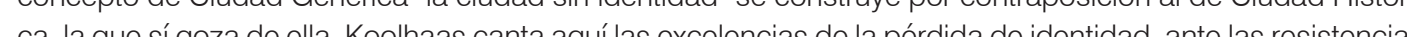

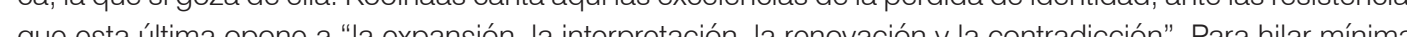
que esta un tra opone a la expansión, la interprexación, la renovación y la contradicción. Para hlar mínima-

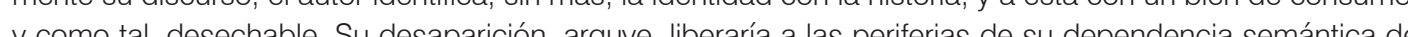

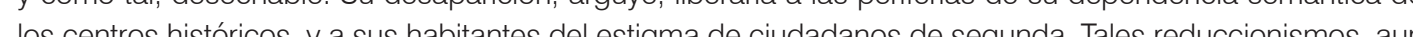
entreverados de intuiciones, marcan los momentos más bajos del vuelo intelectual de Rem Koolhaas. 